\title{
The Study of Tubing Vibration Mechanism in High Pressure Gas Well
}

\author{
Jingbing Luo ${ }^{1}$, Kui Zhang ${ }^{2 *}$, Junlin Liư ${ }^{1}$, Lingyu Mu², Fujun Wang1 \\ ${ }^{1}$ Research Institute on Drilling \& Production of PetroChina Qinghai Oilfield Company, Jiuquan, China \\ ${ }^{2} \mathrm{CNPC}$ Engineering \& Technology Research Institute Co., Ltd., Beijing, China \\ Email: *zhangkuidri@cnpc.com.cn
}

How to cite this paper: Luo, J.B., Zhang, K., Liu, J.L., Mu, L.Y. and Wang, F.J. (2021) The Study of Tubing Vibration Mechanism in High Pressure Gas Well. World Journal of Engineering and Technology, 9, 128-137. https://doi.org/10.4236/wjet.2021.91010

Received: October 30, 2020

Accepted: February 7, 2021

Published: February 10, 2021

Copyright $\odot 2021$ by author(s) and Scientific Research Publishing Inc. This work is licensed under the Creative Commons Attribution International License (CC BY 4.0).

http://creativecommons.org/licenses/by/4.0/

\section{(c) (i) Open Access}

\begin{abstract}
Deep gas wells and gas fields have the characteristics of high pressure. The vibration of the tubing string during the production of gas wells causes the string to be subjected to severe stress and even dynamic fatigue failure. Therefore, this article is based on the dynamic finite element theory, aiming at the characteristics of large-size tubing strings in deep gas wells. The finite element mechanics model and mathematical model of the tubing string vibration of the packer of high-pressure gas wells were established, and the ANSYS software was re-developed. The finite element analysis program for the vibration dynamics of the unbuckled and buckled strings of gas wells was compiled with APDL, and the displacement of the longitudinal vibration of the tubing string of high-pressure gas wells was studied. According to different sizes of tubing strings currently used in deep gas wells and gas fields, simulation calculations are carried out, and the axial impact load and buckling damage laws of the tubing strings of the entire well section under different production rates are obtained. It provides a theoretical basis for the prediction of tubing string vibration law and measures to prevent tubing string vibration.
\end{abstract}

\section{Keywords}

Deep Gas Well, High Pressure, Gas Well, Tubing, Vibration, Damage, Buckling, Finite Element

\section{Introduction}

The deep gas well gas field is the main gas field of the "West-East Gas Transmission" project. It is a typical "three high" gas field [1]. The gas field has high formation pressure. Its single well has a production rate of $100 \times 10^{4}-150 \times 10^{4}$ $\mathrm{m}^{3} / \mathrm{d}$. The production tubing is $27 / 8 ", 31 / 2 "$ and $4 "$ tubing in three sizes [2] [3]. 
During the exploitation of natural gas wells, the high-speed flow of gas causes serious vibration of the tubing, which makes the tubing bear alternating loads. The alternating load caused by vibration may cause the threaded joint of the tubing to loosen and cause leakage, and the tubing is prone to fatigue damage [4]. The current domestic research on vibration of high-pressure gas wells is underway. For example, H Fan [5] and others established a fluid-structure coupling vibration model. Combined with the initial and boundary value conditions of the completion string system, the corresponding computer program was compiled using MATLAB language, and the process of coupling vibration response between fluid and string was calculated and analyzed. L Zhang [6] et al. deduced the lateral vibration equation of the test string for natural gas transportation based on the Hamilton (Ham ilton) principle. The calculation equations of the critical velocity of the transverse vibration frequency and instability of the test string are given, and the influence of the fluid velocity in the pipe on the vibration frequency and stability of the string is discussed. Q Peng [7] et al. established an eight-equation model of in-plane vibration of high-pressure gas well production tubing considering natural gas flow rate, pressure, axial force of the tubing string, and gravity. It is concluded that with the increase of natural gas flow rate, pressure, and axial force of the pipe string, the natural frequency of the production pipe string gradually decreases until it becomes unstable. According to the above-mentioned literature research, most of the current researches mainly focus on the lateral vibration and stability of high-temperature and high-pressure gas well test strings and the research and analysis of fluid-solid coupling vibration of high-pressure gas well completion strings, and there is no specific focus on tubing. Analysis and research of longitudinal vibration.

This article is based on dynamic finite element theory. For deep gas wells and high pressure gas wells, a finite element mechanical model and a mathematical model for the vibration of the tubing string of the packer of high pressure gas wells are established. The second development of ANSYS software was carried out, and the finite element analysis program for the vibration dynamics of the unbuckled string and the buckled string of the gas well was compiled with APDL. The longitudinal vibration displacement and alternating stress of the tubing string in high pressure gas wells are studied, and the axial stress change and buckling damage of the tubing string in the entire well section is studied in depth. It is of great significance to the prediction of tubing string vibration and the prevention of vibration hazards.

\section{The Finite Element Dynamics Prediction Model of Tubing Vibration}

The tubing with packer is fixed at both ends of the downhole [8], the wellhead is fixed at the tubing and at the bottom hole packer. After the tubing packer is set, the tubing has a certain effect on the packer. The tubing must have a "neutralization point". The tubing above the neutral point bears a certain tensile force, 
the tubing at the wellhead has the largest tensile force, and the tubing below the neutral point bears a certain tensile force. Compressive force, the tubing withstands the maximum compressive force at the packer. If this compressive force exceeds the first critical load value of the tubing's structural size, then a part of the bottom tubing below the neutral point will undergo positive rotational buckling or spiral buckling. This situation is not allowed. In order to eliminate the occurrence of buckling of the tubing string, a certain tensile force can generally be raised to reduce the pressure at the bottom of the tubing string. In any case, after the packer tubing is set, under the action of the tubing's own gravity, the tubing is already under force. If there is no packer, the tubing, except for the tension caused by its own gravity, is also affected by the wellbore. The compressive force exerted by the buoyancy of the fluid. If it has a packer, it is also restricted by the packer. The packer may produce compressive or tensile force on the tubing, depending on the working conditions of the tubing. Such as whether the tubing is in the production tubing, or the fracturing or acidizing tubing.

From the above analysis, it can be seen that after the tubing with packer is set, there must be a certain force in the tubing, that is, there must be prestressed. Above the neutral point is the tensile force, and below the neutral point is the compressive prestress. When studying the dynamics of a tubing of several kilometers long, the pre-stress problem must be considered, otherwise it will not meet the actual working conditions. In fact, most scholars in the past did not consider the issue of prestressing. In addition, few scholars conducted dynamic analysis on the entire tubing of the entire well section. Their research only took a small section for research, and ignored the gravity problem. Use the existing three-bending moment equations for mechanical-mathematical modeling analysis. In this paper, the mechanical modeling of the tubing of the entire well section and its dynamic analysis are carried out.

If the tubing does not buckle, it is straight. Then friction and wear damage will not occur when the string vibrates. The previous analysis shows that the string may not have buckling deformation damage under static load. However, in high pressure gas wells, due to the induction of high-speed airflow, the tubing string undergoes shock vibration. Since both ends of the string are fixed, within the elastic body of the slender string, the elastic wave of shock vibration vibrates and propagates back and forth in the longitudinal direction of the string. If the pressure generated by this elastic wave exceeds the critical load of the string, the string will produce sinusoidal buckling or spiral buckling damage. At the same time, contact with the inner wall of the casing causes friction and wear damage. This situation often occurs in small-sized strings, and should be avoided as much as possible in actual production wells. The dynamics of tubing string vibration is a very complicated process, mainly because the tubing string is a slender string. At the same time, due to the limitation of the wellbore space, when the tubing string buckles under pressure, any position of its compressed part may come into contact with the wellbore, which further complicates the force of the tubing string. First, perform mechanical analysis on the string con- 
strained by the packer to determine whether the string has buckled, calculate the buckling state of the string for the buckled string, and then establish a finite element model based on the calculation result as the initial condition of the initial wellbore string [9]. The dynamic finite element models of the vertical tubing and the buckling tubing are shown in Figure 1 [10].

Let's take an example to study the vibration mechanism of the tubing. A well has a 4" production tubing with a depth of $3885 \mathrm{~m}$ under the tubing. The current output is $50 \times 10^{4} \mathrm{~m}^{3} / \mathrm{d}$. According to the buckling analysis of the tubing, the wellbore can be obtained. The initial condition of the tubing is that the tubing does not buckle, so the initial model of the simulation analysis is shown in Figure 1(b). The frictional resistance between the high-speed fluid and the tubing is the shock load that causes the tubing to vibrate. The load changes with the change of gas well production. According to the gas flow analysis of different sizes of tubing, the relationship between impact load and production can be obtained as shown in Figure 2. It can be seen from the figure that the impact load increases with the increase in yield and decreases with the increase in tubing size.

\section{Transient Dynamic Equation}

Sun Tai dynamics method is used to study the vibration of the tubing. Transient dynamic analysis is a method used to determine the dynamic response of structures subject to arbitrary time-varying loads. The basic equation solved by transient dynamic analysis is shown in the following formula (1-1) [11] [12].

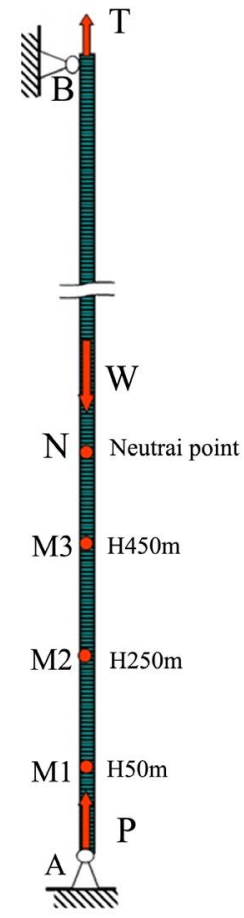

(a)

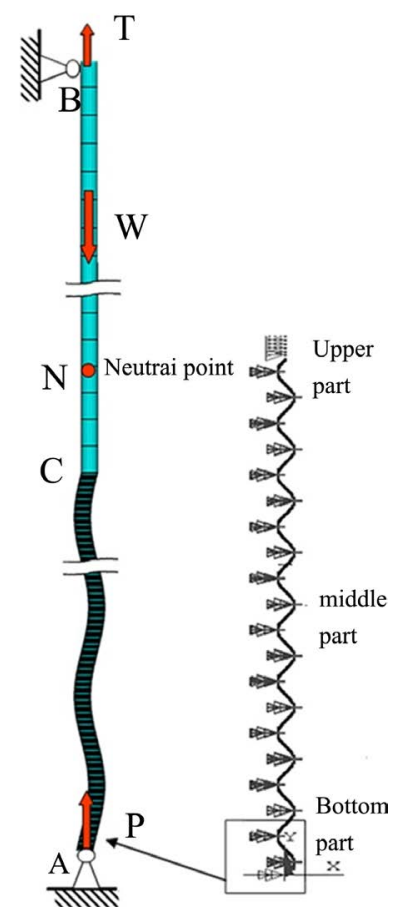

(b)

Figure 1. Finite element dynamic model of tubing vibration. (a) Non-buckling tubing; (b) Buckling tubing. 


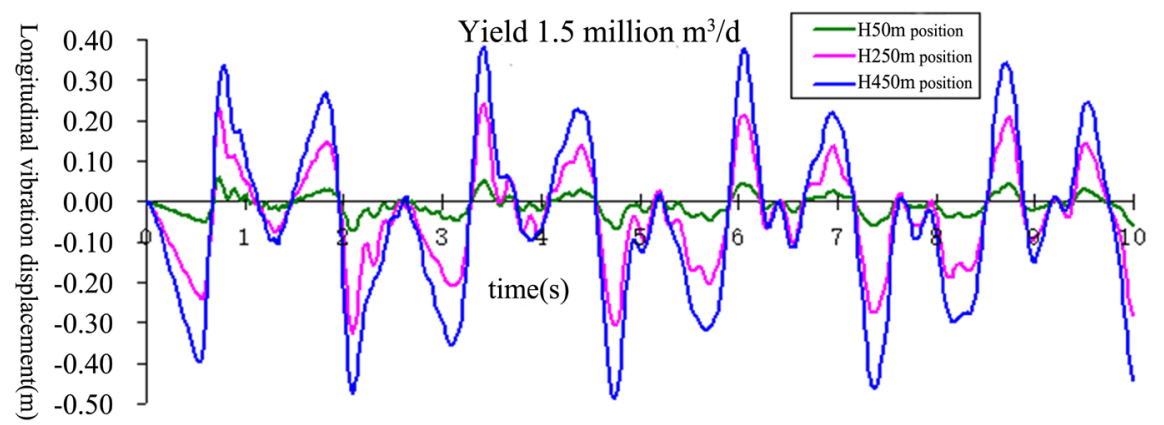

Figure 2. Vibration displacement of tubing by output $50 \times 10^{4} \mathrm{~m}^{3} / \mathrm{d}$.

$$
[M]\{\ddot{U}\}+[C]\{\dot{U}\}+[K]\{U\}=\{F(t)\}
$$

In the formula: $[M]$-mass matrix; $[C]$-damping matrix; $[K]$-stiffness matrix; $\{\ddot{U}\}$-nodal acceleration vector; $\{\dot{U}\}$-nodal velocity vector; $\{U\}$-nodal displacement vector.

For any time $t$, Equation (1-1) can be expressed as a series of static equilibrium equations considering inertial force $([M]\{\ddot{U}\})$ and damping force $([C]\{\dot{U}\})$. ANSYS software uses the Newmark time integration method to solve these equations at discrete time points, and the integration time step is the time increment of successive time points.

For the small-amplitude vibration of the elastic body of the discretized model, the dynamic balance equation can be directly obtained by introducing the inertial force on the basis of the static balance equation (the stiffness equation) according to the D'Alembert principle [13]. One equation:

$$
\iiint_{v^{e}}[N]^{\mathrm{T}}\{p\} \mathrm{d} v+\iint_{s^{e}}[N]^{\mathrm{T}}\{q\} \mathrm{d} s+\{f\}^{e}=\iiint_{v^{e}}[B]^{\mathrm{T}}[D][B] \mathrm{d} v\{u\}^{e}
$$

In the formula: $\{p\}$-body force; $\{q\}$-surface force; $\{f\}^{e}$-element concentration vector; $\{u\}^{e}$-element node displacement vector.

When considering the inertial force of the elastic body itself, the physical force is

$$
\left\{p^{\prime}\right\}=\{p\}+\left\{p_{m}\right\}
$$

In the formula: $\left\{p_{m}\right\}$ Where is the inertial force inside the unit, generally speaking, it is a function of coordinates $x, y, z$.

$$
\left\{p_{m}\right\}=-\rho\{\underline{\ddot{u}}\}=-\rho[N]\{\ddot{u}\}^{e}
$$

In the formula: $\{\underline{u}\}$ Where is the displacement inside the unit, which is a function of coordinates.

$$
\begin{aligned}
& \{\underline{u}\}=[N]\{u\}^{e} \\
& \{\underline{u}\}=[N]\{\ddot{u}\}^{e}
\end{aligned}
$$

Therefore, just replace $\{p\}$ in formula (1-2) with $\left\{p^{\prime}\right\}$, the dynamic balance equation can be obtained, 


$$
\begin{aligned}
& \iiint_{v^{e}}[N]^{\mathrm{T}}\{p\} \mathrm{d} v+\iint_{s^{e}}[N]^{\mathrm{T}}\{q\} \mathrm{d} s+\{f\}^{e} \\
& =\iiint_{v^{e}}[B]^{\mathrm{T}}[D][B] \mathrm{d} v\{u\}^{e}+\iiint_{v^{e}} \rho[N]^{\mathrm{T}}[N] \mathrm{d} v\{\ddot{u}\}^{e}
\end{aligned}
$$

Order

$$
\begin{gathered}
{[m]^{e}=\iiint_{v^{e}} \rho[N]^{\mathrm{T}}[N] \mathrm{d} v} \\
{[M]=\sum[m]^{e}} \\
\{P\}=\sum\left(\iiint_{v^{e}}[N]^{\mathrm{T}}\{p\} \mathrm{d} v+\iint_{s^{e}}[N]^{\mathrm{T}}\{q\} \mathrm{d} s+\{f\}^{e}\right)
\end{gathered}
$$

Therefore, formula (1-7) can be rewritten as

$$
[M] \ddot{u}+[K] u=\{P\}
$$

when there are enough displacement boundary constraints, the value of some elements in $\{u\}$ is known. The corresponding value in $\{\ddot{u}\}$ is also known. Therefore, the mass matrix can be processed in the same way as the stiffness matrix.

When it can be proved that as long as there are enough constraints, the uniform mass matrix $[\mathrm{M}]$ is also symmetric and positive definite, and has the same band shape as the stiffness matrix $[K]$ (because the assembly process is exactly the same).

The finite element method can be used to analyze structural vibration problems and dynamic response problems. The object needs to be discretized into a finite number of unit bodies. However, when considering the characteristics of the element at this time. The load on the object must also consider the inertial force of the element $-\rho \ddot{d} \mathrm{~d} v$ and the damping force $-v d \mathrm{~d} v$ and other factors, where is $\rho$ the density of the structural material; $v$ is the linear damping coefficient. There are in statics problems $d=N q, \varepsilon=B q, \sigma=D B q$. Only when the number of elements increases so that there is enough nodal displacement, the formula $d=N q$ is an approximate expression of the displacement function. The stiffness matrix $K^{e}$, mass matrix $M^{e}$ and damping matrix $C^{e}$ of the element are respectively;

$$
\begin{aligned}
& K^{e}=\int_{v} B^{\mathrm{T}} D B \mathrm{~d} v \\
& M^{e}=\int_{v} N^{\mathrm{T}} \rho N \mathrm{~d} v \\
& C^{e}=\int_{v} N^{\mathrm{T}} v N \mathrm{~d} v
\end{aligned}
$$

Generally speaking, the damping coefficient $v$ is related to frequency. The commonly used approximation is to use Rayleigh damping [14],

$C^{e}=\alpha M^{e}+\beta K^{e}, K^{e}, M^{e}, C^{e}$ of unit, must be used to group the entire structure. So without considering the volume force, the dynamic equation of the entire tubing structure is

$$
M \ddot{q}+C \dot{q}+K q=f
$$

when $f=0, C=0$, The undamped dynamic equation when is free to vibrate;

$$
M \ddot{q}+K q=0
$$


For simple harmonic vibration, there are

$$
q=\delta \sin \omega t
$$

In the formula, $\delta$ is the nodal amplitude array (or vibration mode) of nodal displacement $q ; \omega$ is the frequency; $t$ is the time.

Substitute formula (1-15) into formula (1-12) to get

$$
\left(-\omega^{2} M+K\right) \delta=0
$$

According to the theory of free vibration, the free vibration equation of a $n$-order degree of freedom system should have $n$ natural frequencies and can be determined by the frequency determinant $\omega_{i}(i=1,2,3, \cdots, n)$,

$$
\left|K-\omega^{2} M\right|=0
$$

After obtaining, substitute $\omega$ for the Equation (1-16) to obtain the characteristic vector (vibration mode) $\delta$. Since the modal solution\% of formula (1-17) multiplied by any constant is still a solution. The linear combination of different solutions $\delta$ of the same frequency $\omega$ is still a solution, it is agreed to adopt the normalized modal $\delta$. Even if they are orthogonal to $M$,

$$
\delta_{i}^{\mathrm{T}} M \delta_{j}=\left\{\begin{array}{l}
1, i=j \\
0, i \neq j
\end{array}\right.
$$

In the above formulas, the assembly of $K$ matrix and $M$ matrix is the same as the assembly method of $K$ in the finite element method of structural static analysis.

\section{Analysis of Simulation Results}

Because the tubing is limited by the annular space of the wellbore, the tubing of high pressure wells gas wells undergoes severe longitudinal vibration under the impact of high-speed airflow. The longitudinal vibration may cause the threaded joints of the tubing to loosen and cause leakage, and the tubing will be at a low stress level. Fatigue failure occurred. According to the impact dynamic load data, the ANSYS software was re-developed. First, the relationship of the vibration displacement of the tubing with time under the output of $50 \times 10^{4} \mathrm{~m}^{3} / \mathrm{d}$ is studied, and the distances from the packer were $50 \mathrm{~m}, 250 \mathrm{~m}$ and $450 \mathrm{~m}$. The displacement of the tubing longitudinal vibration is studied, and the simulation results are shown in Figure 2. It can be concluded from the figure that the vibration displacement at a distance of $50 \mathrm{~m}$ from the packer is the smallest, and the amplitude increases as the distance from the packer is farther, and the maximum vibration displacement of the tubing is within the range of $(-0.5-0.4) \mathrm{m}$, And it belongs to irregular alternating vibration. Therefore, we should consider designing a shock absorber in the downhole tubing to avoid fatigue damage of the tubing.

In order to further analyze the stress changes of the tubing vibration caused by the high-speed gas flow, for the gas well production rate of $50 \times 10^{4} \mathrm{~m}^{3} / \mathrm{d}$, the 2 $7 / 8$ ", $31 / 2$ " and 4 " Three sizes of tubing, the sensitivity analysis of the vibration dynamic behavior of a well when these three tubing are selected, and the rela- 
tionship curves of the longitudinal stress caused by vibration with the vibration time are shown in Figures 3-5. It can be concluded from the figure: As the size of the tubing increases, the impact load of the tubing decreases rapidly under the same output.

The analysis results of the buckling state of each tubing under vibration at different production rates are shown in Table 1. From the table, it can be concluded that the larger the size of the tubing, the less likely it is to buckle. At present, the maximum production allocation of a Well is $140 \times 10^{4} \mathrm{~m}^{3} / \mathrm{d}$. The use of 7" tubing can ensure that the tubing does not buckle, and the $31 / 2$ " tubing buckles when the output is $20 \times 10^{4} \mathrm{~m}^{3} / \mathrm{d}$.

Table 1. Buckling damage law of tubing different production.

\begin{tabular}{ccccc}
\hline & \multicolumn{3}{c}{ Yield } \\
\cline { 2 - 5 } Column size & 0 & $20 \times 10^{4} \mathrm{~m}^{3} / \mathrm{d}$ & $90 \times 10^{4} \mathrm{~m}^{3} / \mathrm{d}$ & $140 \times 10^{4} \mathrm{~m}^{3} / \mathrm{d}$ \\
\hline $27 / 8 "$ & no & spiral & spiral & spiral \\
$31 / 2^{\prime \prime}$ & no & no & Sine & spiral \\
$4^{\prime \prime}$ & no & no & no & no \\
\hline
\end{tabular}

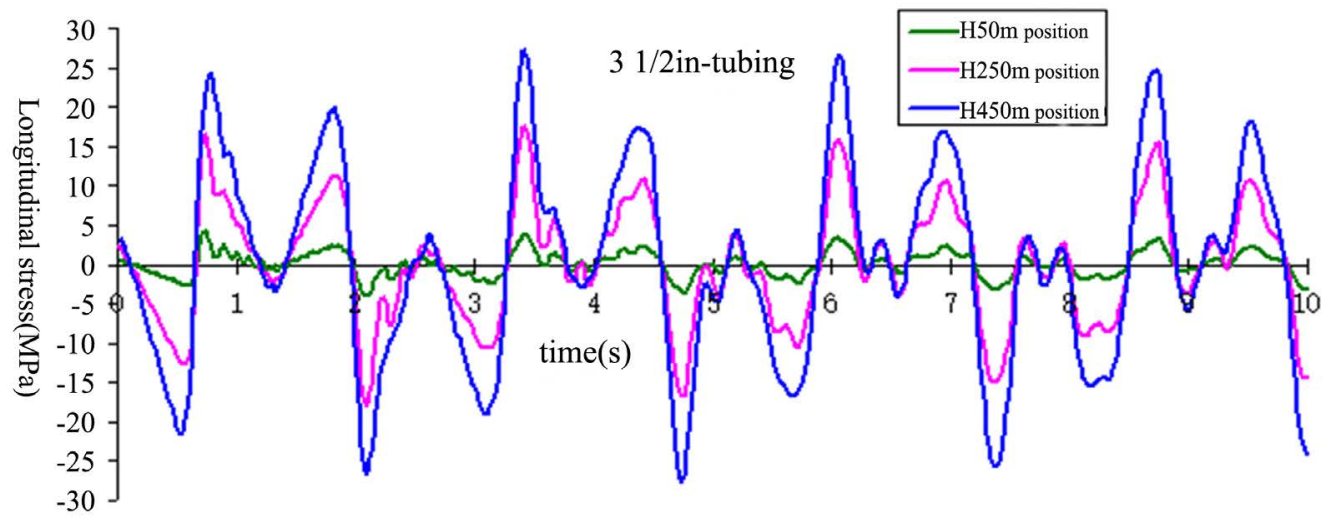

Figure 3. Axial shock load distribution for $27 / 8$ " tubing.

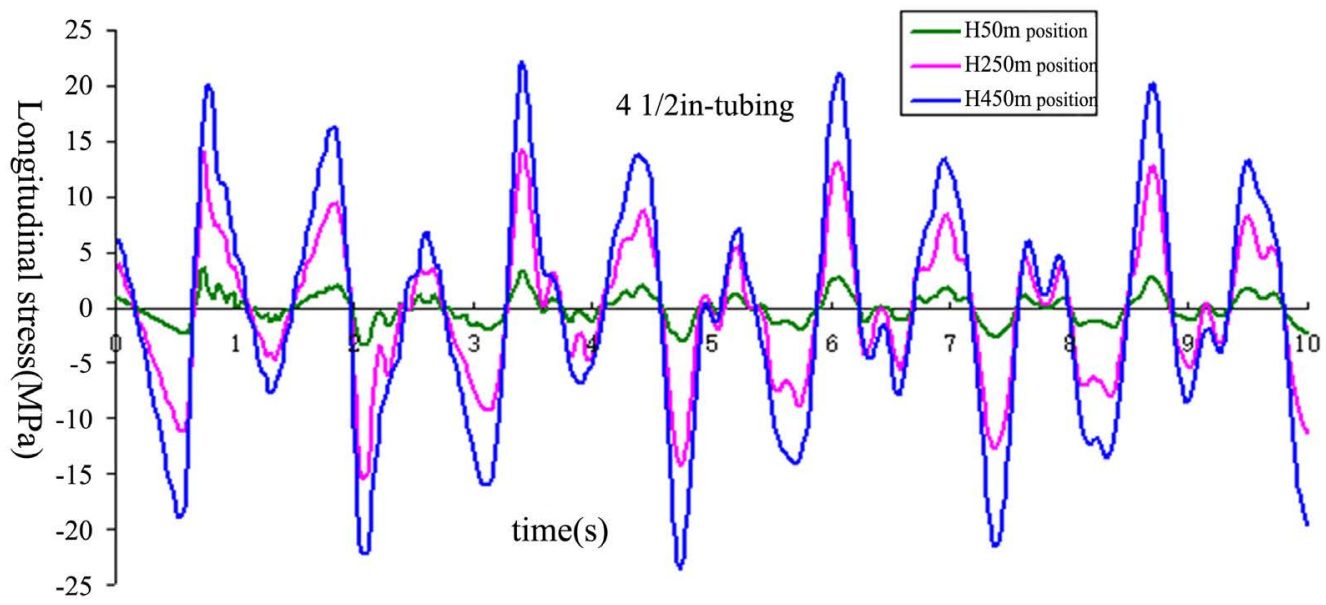

Figure 4. Axial shock load distribution for $31 / 2$ " tubing. 


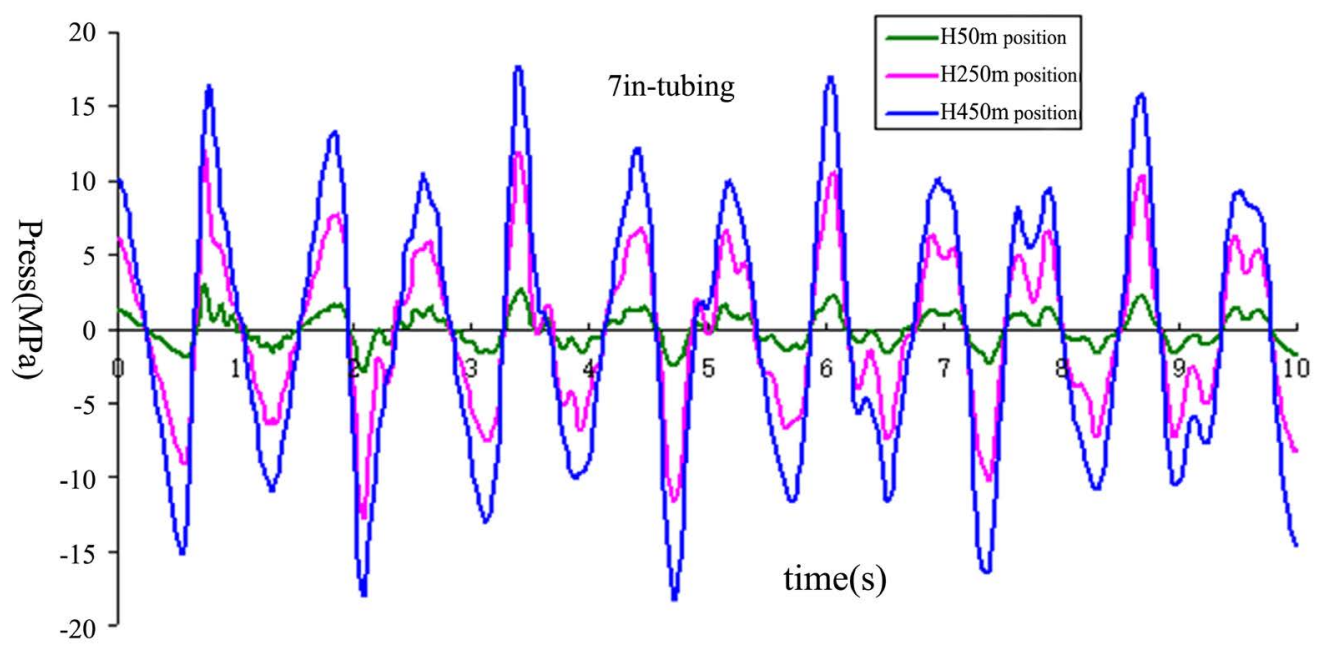

Figure 5. Axial shock load distribution for 4 1/2" tubing.

\section{Conclusions}

1) The research results obtained in this chapter provide dynamic load data of alternating stress for the study of fatigue life prediction of tubing string.

2) According to the characteristics of large-size tubing strings in deep gas wells and gas fields, a dynamic finite element model for non-buckling and buckling tubing strings is established. Under the action of high-speed gas, the farther the tubing string is from the packer, the greater the displacement of the tubing string caused by vibration. When choosing large size tubing, tubing vibration can be reduced. According to the study of tubing: the larger the size of the tubing string, the less likely it is to buckle.

3) In order to prevent the vibration problem of the tubing string of high-yield gas wells, it is recommended: a) After the packer is set, give the tubing string a proper pulling force so that the pressure at the bottom of the tubing string is much less than the first critical load of the tubing string; b) select 7 " The above large-size tubing string is completed to reduce the flow rate of gas in high-yield gas wells; c) The shock absorber of the tubing string is developed to reduce its stress amplitude.

\section{Conflicts of Interest}

The authors declare no conflicts of interest regarding the publication of this paper.

\section{References}

[1] Wang, T., Zhang, Q., Wang, J.S., et al. (2008) Application of Safety Management System in Deep Gas Wells and Gas Fields. Natural Gas Industry, 28, 107-109.

[2] Peng, J., Wu, Y., Yang, S., et al. (2005) Research on Completion Technology of Deep Gas Wells with Abnormally High Pressure and High Production in Gas Fields. Natural Gas Industry, 25, 77-79.

[3] Peng, J., Zhou, L., Ruan, Y., et al. (2008) Risk Assessment of High Pressure Gas 
Wells in Deep Gas Wells and Gas Fields. Natural Gas Industry, 28, 110-112.

[4] Cai, Y., Li, Q. and Huang, Z. (1998) Analysis of Solid-Liquid Coupling Vibration of Oil Tubing. Natural Gas Industry, 18, 54-56.

[5] Fan, H., Wang, Y., Zhang, L., Yang, X., Yang, X. and Wei, F. (2011) Fluid-Solid Coupling Vibration Model of High Pressure Gas Well Completion String and Its Application. Acta Petrolei Sinica, 32, 547-550.

[6] Wang, Y., Fan, H., Zhang, L., Wei, F., Feng, G. and Niu, M. (2011) Lateral Vibration and Stability of High Temperature and High Pressure Gas Well Test String. Petroleum Machinery, 39, 36-38+56+96-97.

[7] Fan, H., Yang, X., Wang, Y., Peng, Q., Ma, G., Lai, M. and Deng, S. (2015) Analysis of Lateral Vibration Characteristics of High-Pressure Gas Well Production String. Petroleum Machinery, 43, 88-91+95.

[8] Song, Z. (2010) Study on Dynamic Damage Mechanism of High-Production Gas Well String. Ph.D. Thesis, Southwest Petroleum University, Chengdu.

[9] Mei, F. (2009) About D’Alembert's Principle-The Sixth Reading Notes of Theoretical Mechanics. Mechanics and Practice, 31, 61-63.

[10] Salehi, M. and Sideris, P. (2020) Enhanced Rayleigh Damping Model for Dynamic Analysis of Inelastic Structures. Journal of Structural Engineering, 146, 210-216. https://doi.org/10.1061/(ASCE)ST.1943-541X.0002732

[11] Lian, Z., Lin, T., Liu, J., et al. (2006) Finite Element Analysis of Perforation Vibration of Horizontal Well Oil Tubing. Petroleum Drilling Technology, 28, 56-59.

[12] Wang, M., Zhang, Y. and Gong, C. (2014) Development and Application of Fracturing Balanced Packers for Deep Gas Wells. Collection of Oil Production Engineering 2014 Second Series: Oil Production by Daqing Oilfield Co., Ltd. Engineering Research Institute, Daqing, Vol. 36, 5-7.

[13] Huang, Z. (1998) Force Analysis and Application Research on Oil Tubing of High-Yield Gas Wells. Master's Thesis, Southwest Petroleum Institute, Chengdu.

[14] Jiang, M. (2017) Research and Application of Tubing String Mechanics Model under Complex Working Conditions. Master's Thesis, China University of Petroleum, Beijing. 